\title{
Regarding the vitality of the gastric mucosal tears in the case of exsanguination
}

\author{
Slobodan Nikolić ${ }^{1} \cdot$ Vladimir Živković $^{1}$
}

Accepted: 28 August 2015/Published online: 8 September 2015

(C) Springer Science+Business Media New York 2015

The article "Gastric mucosal lacerations in drowning: resuscitation artifact or sign of death by drowning ("Sehrt's sign")?" by Buschmann et al. [1] suggests that tears of the gastric mucosa may occur after death as the consequence of resuscitation efforts. They describe a case of a deceased who died due to exsanguination following a stab injury to the chest: " $2200 \mathrm{ml}$ of blood was present within the chest cavity," and "the stomach was overinflated but empty," with tears in the cardia, but "without hemorrhage within the surrounding mucosa." The authors concluded that tears had occurred after cardiac arrest, based on the absence of hemorrhage at the edges of these tears. Microscopic examination of the gastric mucosa was not performed since the cause of death had already been identified.

Blood constitutes approximately $7 \%$ of body weight [2] and death by exsanguination occurs following an acute blood loss of approximately $40 \%$ of total blood volume [3]. Centralization of the blood flow is an established compensatory mechanism in shock. This includes activation of the sympathetic nervous system resulting in splanchnic vasoconstriction and reduction of perfusion of the intestine, including the stomach [4]. Therefore, in the setting of severe hypovolemic shock, the wound margins may not be markedly hemorrhagic. This points to a major limitation to the case study-lack of microscopic examination of the gastric mucosa. With aforementioned physiologic alterations in mind, hemorrhagic changes may be subtle and not easily noticeable on gross examination. This may make it difficult to determine the vitality of the gastric mucosal tears based solely on macroscopic appearance. Thus, these lacerations might have occurred while the injured person was still alive, although in profound hemorrhagic shock. In conclusion, microscopic examination may be a key component of the attempts to determine the vitality of the lacerations in the setting of exsanguination.

Acknowledgments This work was supported by Ministry of Science of Republic of Serbia, Grant No. 45005.

\section{References}

1. Buschmann CT, Schmid S, Tsokos M. Gastric mucosal lacerations in drowning: resuscitation artifact or sign of death by drowning ("Sehrt's sign")? Forensic Sci Med Pathol. 2015;11:312-3.

2. Rutty G, Tsokos M. Sequelae of traumatic injuries and causes of death. In: Madea B, editor. Handbook of forensic medicine. Chichester: Wiley Blackwell; 2014. p. 216-52.

3. Dettmeyer R, Verhoff M, Schuetz H. Forensic pathologyfundamentals and perspectives. Heidelberg: Springer; 2014.

4. Mitchel RN. Hemodynamic disorders, thromboembolic disease, and shock. In: Kumar V, Abbas AK, Fausto N, Aster JC, editors. Robbins and Cotran pathologic basis of disease. 8th ed. Philadelphia: Saunders Elsevier; 2010. p. 111-34.
Vladimir Živković

vladinmej1@yahoo.com; vladimir.zivkovic@mfub.bg.ac.rs

1 Institute of Forensic Medicine, University of Belgrade School of Medicine, 31a Deligradska Str., 11000 Belgrade, Serbia 